The evolutionary significance of the change from porphyropsin to rhodopsin, which occurs in some species of amphibia on metamorphosis, is an important and most interesting field of investigation.

\title{
REFERENCES
}

A full list of references to original papers on which the above summary is based would occupy much space. Most of the earlier work is referred to by Morton (Rep. Progr. Chem. 1950, 46, 244). R. Granit (Annu. Rev. Physiol. 1950, 12, 485) reviews recent work on the physiology of vision, and G. Wald (Biochim. Biophys. Acta, 1950, 4, 215) discusses the interconversion of the retinenes and vitamins A in vitro. The following refer to the most recent work:

Bliss, A. F. (1949). Biol. Bull. Woods Hole, 97, 221.

Collins, F. D. \& Morton, R. A. (1950). Biochem. F. 47, 3.

Collins, F. D. \& Morton, R. A. (1950). Biochem. F. 47, 10.

Collins, F. D. \& Morton, R. A. (1950). Biochem. F. 47, I8.

Wald, G., Durell, J. \& St George, R. C. C. (1950). Science, III, 179.

Wald, G. \& Hubbard, R. (1950). Proc. nat. Acad. Sci., Wash., 36, 92.

\section{Standardization and Requirement of Vitamin $\mathbf{A}$}

\author{
By E. M. Hume, Lister Institute of Preventive Medicine, London S.W. I
}

\section{Introduction}

The standardization of vitamin $\mathrm{A}$ and the requirement for vitamin $\mathrm{A}$ are two subjects not very closely allied but they have both received special attention from the Vitamin A Subcommittee of the Medical Research Council's Accessory Food Factors Committee of which I have been the Secretary ever since it was first set up to deal with the standardization of vitamin A. Most of what is now said refers to the joint work of the members of that Subcommittee. There are two stories to be told and both are longer than there is space for, so only that of standardization will be told in full.

It was in I93 I that the Health Organization of the League of Nations held its first conference, aimed at setting up international standards for certain of the vitamins, for at that time there were no methods except biological methods for testing any of the then known vitamins. It was essential to set up standard substances to act as stable yardsticks against which materials could be tested for their potency and to define a fixed amount of the standard substance whose unchanging activity should be the international unit.

\section{Standardization}

\section{Establishment of the carotene standard}

At this first conference carotene was set up as international standard for vitamin A, and it retained this position, not unassailed, until 1949 (Permanent Commission on Biological Standardization: League of Nations, 1931). Indeed it has long been under heavy criticism, mainly on the fundamental ground that it is not vitamin A. Such a criticism had at first little sense, because no satisfactory form of vitamin A itself was available, but by 1939 pure esters of vitamin $A$ had been prepared, and the stage was all set to propose vitamin $\mathrm{A} \beta$-naphthoate as international standard. These plans were 
frustrated by the war and the carotene standard received a new lease of to years of life during which it has been more heavily criticized than ever.

The carotene standard of 1931 was a crystalline mixture of carotenes, and the vitamin A activity of I $\mu \mathrm{g}$. of it was the unit of vitamin A. At a second International Conference in 1934 (Permanent Commission on Biological Standardization: League of Nations, 1934), the preparation of mixed carotenes was changed to one of pure crystalline $\beta$-carotene. The international unit had to be changed correspondingly and, by collaborative biological test, it was established that the amount of the pure substance that had the same activity as $\mathrm{x} \mu \mathrm{g}$. of the mixture was $0.6 \mu \mathrm{g}$. It is very important to maintain the continuity of any international unit and the activity of $0.6 \mu \mathrm{g}$. was accordingly adopted for the new international unit.

Whatever criticisms have been made against the $\beta$-carotene standard, it has to be granted that it has always behaved very well as a stable replaceable substance, which is an essential property for a standard. During the war the supply of it became exhausted, and a fresh preparation was made. It was tested against the original preparation at the National Physical Laboratory and the two curves of spectral absorption were almost exactly superimposed on one another.

\section{Cod-liver oil as standard for vitamin $A$}

The non-existence of any suitable preparation of preformed vitamin $A$ was given as the reason for making carotene the standard, and this was true though vitamin $A$ was available in fish-liver oils and concentrates. They were not generally regarded as suitable, but the International Conference of 1934 decided that it would be advisable to have a sample of cod-liver oil as a subsidiary standard. The United States Pharmacopoeia Advisory Commission had some time before issued a sample of Reference Cod-Liver Oil to be used in the United States as a standard, so the Board of Trustees of the United States Pharmacopoeia were asked whether they would place a quantity of their Reference Oil at the disposal of the Health Organization of the League of Nations. They most kindly and willingly consented to do so. The Reference Oil was tested in twelve laboratories and the value ascribed to it was $3000 \mathrm{i} . \mathrm{u} . / \mathrm{g}$. The U.S.P. unit in terms of the cod-liver oil was to have the same activity as the international unit of $\beta$-carotene.

Unfortunately, cod-liver oil really was more unsuitable as an international standard than had even been supposed, and its adoption introduced a nigger into the wood pile who was not finally liquidated until the belated but felicitous International Conference of 1949 .

Whether the U.S.P. Reference Oil never really possessed the value of $3000 \mathrm{i} . u . / \mathrm{g}$. found for it, or whether it early lost part of that value, it is not now possible to say, but its overvaluation introduced an additional complication into the problem of the conversion factor, to which it is now necessary to turn.

\section{Conversion factor for vitamin $A$}

The conversion factor for vitamin $A$ is the number that relates the spectroscopic readings to the results of biological tests expressed in international units. In considering 
the conversion of carotene into vitamin $A$, it is important to distinguish which kind of conversion is meant at the moment of discussion. Superficially and qualitatively the two expressions mean something quite different, but fundamentally and quantitatively the problem of the conversion of spectroscopic readings into international units is the problem of the quantitative conversion of carotene to vitamin $A$.

Although biological standardization may be necessary for a substance, there goes on all the time the battle to establish some physical or chemical means of measuring it so that the biological standard may be eliminated. This struggle is carried on very strongly by the commercial firms in their anxiety to rid themselves of the cumbrous and expensive procedure of biological testing. Vitamin $A$ is bought and sold in terms of international units. All commercial firms dealing in vitamin A would like to use the physical method of determining vitamin A content if they could trust it, but sellers would like a high conversion factor, seeming to give them a large number of international units, while buyers would like a low conversion factor, seeming to give them a small number of international units, for the identical article.

The report of the 1931 International Conference says nothing at all about any spectrophotometric test for vitamin A. The report of the 1934 Conference makes the guarded statement 'It has been found that, within certain defined conditions, measurement of the coefficient of absorption $(E)$ at $328 \mathrm{~m} \mu$. affords a reliable method for measuring the vitamin A content of liver oils and concentrates. As a means of converting values obtained for $E_{1 \mathrm{~cm} .}^{1 \%} 328 \mathrm{~m} \mu$. into a figure representing the International Units of Vitamin A per gramme of the material examined, the factor 1600 is recommended for adoption' (Permanent Commission on Biological Standardization: League of Nations, 1934).

When we of the Vitamin A Subcommittee look back on the basis upon which that factor, 1600 , was founded, we have to feel deeply thankful for our good luck. The slender evidence for it is presented by Hume \& Chick (1935). I believe the figure was arrived at largely by Prof. R. A. Morton and must have been almost inspirational from the tough way in which it has held its ground, and still holds it for certain materials and with certain necessary qualifications. The adoption by the International Conference of the value, I600, was provisional, and after the Conference it was the immediate task of the Vitamin A Subcommittee to try to put the value for the conversion factor on a sounder basis.

\section{The three collaborative trials}

For a long time at any rate, for various inherent reasons, the biological test for vitamin A yielded results that were subject to greater variations than the results of other biological tests. It was consequently necessary to enrol as many laboratories as possible, and use as many animals as possible, to carry out the tests. Three main trials were made in each of which some dozen laboratories participated, the commercial firms taking an equal part with the members of the Vitamin A Subcommittee.

When the first test (Hume, 1937) was made, ideas were current that a conversion factor of about 2000 was attached to some cod-and halibut-liver oils, whereas one more like 1000 was associated with some concentrates. The materials chosen for test were, 
therefore, a rich halibut-liver oil and a concentrate of its unsaponifiable fraction. The respective conversion factors obtained were 1470 for the halibut-liver oil, and about 1000 for the concentrate. The value 1470 did not disagree too badly with the provisional figure of 1600 for oils, and provided no basis for changing it, and that of 1000 was in accordance with current experience of concentrates. When the results of the tests had been fully analysed statistically the value for the halibut-liver oil was found to be 1570 instead of 1470 , and the agreement with the value of 1600 provisionally recommended by the International Conference of 1934 was striking. Fortunately, in planning our experiment, we had arranged for spectrophotometric control of all the vitamin A solutions used in the biological experiments, and residues were returned by all the participants at the end of their feeding tests. This was a great advance, and was a procedure that we always afterwards followed. The spectrophotometric tests made it quite clear that the concentrate of unsaponifiable fraction was unstable and had deteriorated during the biological tests. The results of the biological tests would, therefore, give too low a conversion factor when referred to the spectroscopic reading made at the beginning of the whole investigation. The set of discrepant conversion factors round about 1000 which depended on the instability of the alcohol form of vitamin A was thus disposed of.

Meanwhile, in the United States, a value of 2000 for the conversion factor was taking stronger and stronger hold. It was the habit there to use the U.S.P. Reference Oil as standard of reference more often than the international $\beta$-carotene standard, and it appeared that a conversion factor of about 2000 was commonly obtained when rich oils were tested against the Reference Oil. The suspicion was gaining ground in England that the Reference Oil was overvalued and did not really possess its declared potency of $3000 \mathrm{i} . \mathrm{u} . \mathrm{g}$. Whispers to the same effect came from America also. If it were indeed so, oils tested against it would be overvalued too, and the number relating their value in international units to the spectrophotometric reading would be too large.

The Vitamin A Subcommittee decided, therefore, to make a collaborative test of the U.S.P. Reference Cod-Liver Oil against the $\beta$-carotene standard. The same procedure was followed as before, and the value obtained on the unsaponifiable fraction of the oil was $26 \mathrm{rg}$ i.u./g. instead of the declared value of 3000 . All substances tested against it would, therefore, be overvalued by rather more than $12 \%$. The conversion factor found was 1820 , and though less than 2000 was still high (Hume, 1939).

A further complication ensued from the overvaluation of the U.S.P. Reference Oil. The U.S.P. unit was defined in terms of the Reference Oil and was officially identical in value with the international unit. In fact, the overvaluing of the Reference Oil meant that the U.S.P. unit was worth about 12 or $13 \%$ less than the international unit.

The longer such a state of affairs went on, the more desperately involved the situation must become, between usage in Great Britain and in the United States. When the solid estẹrs of vitamin A first described by Hamano (1935, 1937) were prepared in the pure state by Mead (1939), the possibility appeared of solving the whole complicated situation by changing the international standard from $\beta$-carotene to an ester of vitamin A. The third collaborative test was, therefore, started in 1939 to make the comparison between vitamin $A \beta$-naphthoate and the international standard $\beta$-carotene. 
The tests were completed with difficulty and the international conference with a view to which they were made was never held. 'The conversion factor obtained was 1770 (Hume, 1943). The values found in the two previous collaborative experiments of I 570 and I 820 had been regarded as significantly different but when the intermediate value of $177^{\circ}$ was obtained in the third experiment, it was considered that the three did not differ significantly and could be pooled to give the value of 1740 .

The result was published during the war but, since no international conference could be held, the original provisional figure of 1600 continued to be used in the United Kingdom while that of 2000 was being used in the United States. Britain became a large purchaser of vitamin A from the United States, for inclusion in the ration margarine, and the two different conversion factors were a constant source of irritation and embarrassment to the Ministry of Food. From the other side of the Atlantic, it appeared that vitamin A was lost in the Atlantic, for it started out labelled with a certain value in U.S.P. units, but on arrival in England was labelled with a smaller number of international units in spite of the fact that no difference between the value of these two units could be officially recognized in the United States. Goodwill overcame the difficulties somehow and we got our vitaminized margarine.

When the war was over, it was more clear than ever that some drastic change would be needed to solve the complicated muddle into which the whole question of vitamin $A$ standardization had got. It had not been possible during the war to do any more work in the United Kingdom towards devising a new standard, but those who had to evaluate the vitamin A concentrates for margarine derived an enormous amount of valuable experience through the mass of material which they had to handle. Prof. Morton's laboratory was able to elaborate the spectrophotometric method of testing and the workers for Messrs Lever Bros. and Unilever Ltd. gave much attention to the biological test.

\section{Vitamin $A$ acetate as international standard for vitamin $A$}

Meanwhile, in the United States, it had been possible to continue research on the preparation of pure esters of vitamin A. Of those prepared the acetate seemed more suitable than the $\beta$-naphthoate, and the most suitable to act as a new international standard, and a collaborative study of the same sort as those made by the Vitamin A Subcommittee was organized and carried out for the United States Pharmacopoeia Vitamin Advisory Board. Biological tests of the acetate against $\beta$-carotene were made in some twelve laboratories, with a simultaneous spectrophotometric test and a statistical analysis of all the results. As the result of these tests, the United States Pharmacopoeia Vitamin Advisory Board announced a solution of vitamin A acetate as their new Reference Preparation to replace the Reference Cod-Liver Oil. The amount of the acetate found equivalent to I i.u. $(0.6 \mu \mathrm{g}$ ) of $\beta$-carotene was $0.344 \mu \mathrm{g}$. (or $0.3 \mu \mathrm{g}$. vitamin A alcohol), so that $\mathrm{I} g$. of the pure substance must contain

$$
\frac{I}{0.3} \times 10^{6}=3.3 \text { million i.u. }
$$

The spectrophotometric $E$ value, $E_{1 \mathrm{~cm}}^{1 \%}$. at $328 \mathrm{~m} \mu$., is accepted as just about $175^{\circ}$ 
in certain solvents. From our definition of the conversion factor then, the value for it must be 3.3 million divided by $175^{\circ}$ which is just about 1900 . The actual figure mentioned by the U.S.P. Vitamin Advisory Board was 1894 .

About the time that the work on vitamin A acetate for the U.S.P. Vitamin Advisory Board was completed, the World Health Organization was being set up, linked for a time with the old League of Nations Health Organization by an Interim Commission.

The Interim Commission decided to hold an international conference on biological standardization and, through the Department of Biological Standardization at the National Institute for Medical Research, the Accessory Food Factors Committee was asked to prepare a brief on vitamins $A$ and $D$.

To us of the Vitamin A Subcommittee it appeared that the devising and testing of the new standard had been done for us in the United States and that we need not carry out any further tests ourselves, if we could be allowed to inspect the details of the United States tests. We could not conscientiously recommend the results for adoption unless we had been allowed to satisfy ourselves of their statistical validity. 'This opportunity was obtained for us by Dr E. M. Nelson of the Federal Security Agency, Food and Drugs Administration in Washington, at whose request Dr E. Fullerton Cook, Chairman of the U.S. Pharmacopoeia Vitamin Advisory Board, placed the data in our hands. They were examined for us by $\mathrm{Dr} J$. O. Irwin who has always been the statistician associated with the work of the Vitamin A Subcommittee. He reported favourably on the statistical treatment of the results and we were greatly relieved to feel that we had not to undertake yet another collaborative investigation.

\section{The relation of the conversion factors found in the United Kingdom to that found for vitamin $A$ acetate}

The conversion factor found for the acetate was 1900 , and it is necessary to consider how far this value is compatible with the factor of 1600 provisionally recommended by the International Conference of 1934 , and with the factors of 1570,1820 and $177^{\circ}$ found by the Vitamin A Subcommittee in their three collaborative experiments.

Nothing has so far been said about the question of irrelevant absorption which is one of the major factors complicating the spectrophotometric measurement of vitamin A. In this country it has essentially been the field of Prof. R. A. Morton, first in collaboration with Dr J. R. Edisbury and later with Mr T. W. Goodwin and Dr A. L. Stubbs. They have worked on it continuously and have brought the difficulty well under control.

The irrelevant absorption is the spectral absorption at or near the maximum absorption of vitamin $A$, which is caused by the presence of other substances devoid of vitamin A activity. A large part of it can be eliminated by saponification. It does not, of course, affect pure substances, and is more important the greater its magnitude in relation to the amount of vitamin $A$ present. The more it inflates the spectrophotometric reading in relation to the biological value, the smaller will be the conversion factor.

Of the three conversion factors, 1570,1820 and 1770 , obtained by the vitamin $A$ Subcommittee, the last was with a pure substance, vitamin A $\beta$-naphthoate, and the second was with an unsaponifiable fraction; only the first, the lowest, was with a whole 
oil. The first, therefore, was the only one in which irrelevant absorption might have played a part. By great good fortune, a portion of the original halibut-liver oil used for the first test was still in existence in satisfactory cold storage, and Prof. Morton was able to retest it spectrophotometrically, after eliminating the irrelevant absorption. The corrected value thus obtained for the conversion factor was $183^{\circ}$ instead of 1570 (Morton \& Stubbs, 1947).

In preparation for the International Conference by that time definitely announced by the Interim Commission, the Vitamin A Subcommittee asked Dr Irwin to examine the original data and combine these three conversion factors and the U.S. Pharmacopoeia value of $\mathrm{I} 894$ in one figure. He did so and the value he found was $\mathrm{I} 837$ with fiducial limits at $P=0.99$ of $94-106 \%$. Any value between 1800 and 1900 would thus be possible.

On both sides of the Atlantic, the data were thus all ready for presentation to the International Conference.

The World Health Organization finally came into being in succession to the Interim Commission, and its Expert Committee on Biological Standardization created a Subcommittee on Fat-Soluble Vitamins. The Subcommittee met in London on 26-29 April 1949. With Sir Edward Mellanby in the Chair, Dr R. Gautier as Secretary and many other familiar faces, the Conference was in full continuity with its predecessors of $193 \mathrm{I}$ and 1934. It was a most felicitous Conference which reached its decisions with complete unanimity.

The United States had already grasped its worst nettle when it made the new U.S. Pharmacopoeia unit based on vitamin A acetate equal to the potency of $0.6 \mu \mathrm{g}$. of $\beta$-carotene instead of making it equal to one unit of the old, overvalued Reference Oil. This must have meant writing down the value of great stocks of vitamin A. Nothing, therefore, stood in the way of accepting the acetate and the new U.S.P. unit as international standard and international unit, respectively.

If the value of $0.34 \mu \mathrm{g}$. was accepted as the value for the unit, there could be no argument about the conversion factor because the spectrophotometric value for pure vitamin A acetate was generally accepted. The conversion factor had to be 1900 , and there was no longer anything in the British results to conflict with it, as long as irrelevant absorption was ruled out.

The Expert Subcommittee was, therefore, able in full harmony to recommend the acceptance of vitamin $A$ acetate as international standard for vitamin $A$, with the activity of $0.34 \mu \mathrm{g}$. of it, or $0.3 \mu \mathrm{g}$. of vitamin $\mathrm{A}$ alcohol, as the unit, and 1900 as the conversion factor attached to it. The serviceable old $\beta$-carotene standard was retained for biological estimations of carotenoids. These recommendations have since been accepted by the superior bodies (World Health Organization, 1949) and are in the press.

\section{The conversion of carotene to vitamin $A$}

Out of this long research on the magnitude of the conversion factor comes clearly a conclusion of fundamental importance.

If $0.3 \mu \mathrm{g}$. of vitamin $\mathrm{A}$ has the same activity as $0.6 \mu \mathrm{g}$. of $\beta$-carotene, which is the essential biological result, then the molecule of $\beta$-carotene does not split into two 
molecules of vitamin A as was long supposed, but produces only one. At any rate that is the average result of all the four collaborative researches which have been mentioned. There is some evidence that conditions exist in which it is not always so, but in the conditions of the collaborative experiments it was so.

\section{Relative value of the biological and spectrophotometric tests}

At times in these 20 years, controversies have blown up that the biological test or the spectrophotometric test was no use at all, but of course the truth is that both were essential.

It is true that the biological test is not at all accurate but the spectrophotometric test is valueless as a test of biological activity if it is not checked all along the line by the biological test.

To attain any degree of accuracy the biological test requires so cumbersomely many animals that it is the aim of all to eliminate it in favour of the spectrophotometric test, wherever it has been established that that can reliably be done.

Now that the dust of battle has died down, it is possible to see the various subjects of conflict in better proportion.

\section{Other concersion factors proposed}

The story has been confined to the things that happened in Great Britain and the United States. Other contributions have been made, and claims have been set up for other conversion factors. There is only one to which the temptation to refer is irresistible, and that is the claim for a conversion factor of 3000 for the German vitamin A concentrate, Vogan. Such a conversion factor was of course very favourable in foreign trade for Nazi economic policy. It is probably better to mention no names of Germans. Some are perhaps fortunately dead and the whole truth is not known.

The claim for the very high conversion factor for Vogan, which was a fish-liver oil concentrate, was based on the fact that the vitamin $A$ in it was mainly in the ester form. The claim was supported by a large, consistent, published series of animal experiments made with rats against a standard at various times of the year. One could not see what could be wrong with them. One fact, however, was suspicious. A test on the U.S. Pharmacopoeia Reference Oil in which there was vitamin A in the ester form did not yield a conversion factor of 3000 . It could not; the facts or approximate facts about the Reference Oil were too well known.

During the war the Swiss Professor Edelbacher challenged the value claimed for Vogan and the Germans were forced to retest it. They did so and found a conversion factor of about 2000 and that the Vogan preparation sold commercially was correspondingly overvalued. The actual value found in the biological tests was 77,000 i.u./g. instead of the 120,000 i.u. claimed. How the original results were obtained has not been explained. Use of a deteriorated carotene standard might produce the effect, but the explanation does not much matter any longer, now the claim is no longer made, and as long as it is known that 0.64 is the factor by which all results obtained against Vogan as standard should be scaled down. 


\section{Requirement of vitamin $A$}

Another main preoccupation of the Vitamin A Subcommittee was a large-scale experiment which attempted to determine the human requirement of vitamin $\mathrm{A}$.

The research was undertaken in response to a request in 1940 made to the Medical Research Council by Sir Jack Drummond, then Chief Scientific Adviser to the Ministry of Food, for more accurate information than was available as to the human requirement in terms of vitamin $A$ and of $\beta$-carotene. When the request came it was obvious that a human experiment was the only way to find an answer, but a supply of human subjects sufficient for the purpose seemed a day-dream. Then it was learnt that such a group existed. It had been built up by $\mathrm{Dr}$ Kenneth Mellanby in Sheffield from conscientious objector volunteers, particularly for research on scabies. A team of investigators was formed including many more than the Vitamin A Subcommittee. At first Dr Kenneth Mellanby and Prof. H. A. Krebs were in charge on the spot. Then Dr Mellanby went abroad and Prof. Krebs took sole charge in Sheffield with the Vitamin A Subcommittee and the rest of the team meeting there about once a month. It sounds a cumbersome way of conducting an experiment but it worked very well. The course of the experiment was so unpredictable from the first, the prime unknown being the length of time it would take to deplete the men on a diet deficient in vitamin A, that it was highly satisfactory to be able to steer the experiment by constantly renewed general discussion, with the opportunity of considering the nutritional state of each of the twenty-three individuals separately every month. Some of them were receiving prophylactic doses of vitamin $A$ or $\beta$-carotene, while others were undergoing depletion with a view to quantitative, curative dosing.

The account of the experiment has been published in full in a Medical Research Council green report (Hume \& Krebs 1949) and is accessible to everyone, so that a little brief comment is all that is necessary.

It must be remembered that very few of the individuals ever became sufficiently depleted to show unmistakable signs of change on dosing. No unequivocal signs of depletion appeared within the ist year. This was in itself a valuable result since previous evidence as to depletion times was conflicting. It harmonizes, however, with the general experience in western Europe during the war, where authentic vitamin A deficiency was scarcely seen, though circumstances must have arisen in which individuals had to subsist on their reserves for certain periods. The existence of such large reserves in the experimental subjects meant that there was only a very small number of persons sufficiently depleted for test dosing.

Requirement in terms of vitamin A. For vitamin A the evidence obtained from a curative test, from prophylactic tests, and from the values found for the liver reserves of persons dying through accident or other violence in Great Britain, led to the conclusion that 1300 i.u. vitamin A could be regarded as the minimum daily protective dose for a healthy adult. 'To allow for individual variation and create a margin of safety it was recommended that 2500 i.u. vitamin $A$ be put forward as the minimum daily requirement for healthy adults. The procedure of doubling the value for the minimum protective dose to secure the requirement has been criticized and is certainly open to criticism. Some such margin has, however, to be created, and it is a matter of judge- 
ment rather than of facts how that should be done. No pronouncement based on the results of the Sheffield experiment can of course be made for the requirements of vitamin $A$ or of carotene for any other class of individuals than healthy adults.

Requirement in terms of $\beta$-carotene. For $\beta$-carotene the assessment of the requirement from the evidence is more difficult because the absorption of the dose given is incomplete to an extent varying with the nature of the vehicle in which it is given.

From prophylactic and curative tests it was concluded that the minimum protective dose, on the assumption that all the $\beta$-carotene administered was absorbed, must lie between $125^{\circ}$ and 1900 i.u. daily for a healthy adult. On the same supposition a figure of 1500 i.u. daily was, therefore, recommended. For the same reasons as were given in connexion with vitamin A, this value was doubled so that the figure 3000 might be regarded as generally applicable to healthy adults.

Since, however, the figure 3000 supposes that all the $\beta$-carotene is absorbed, which is really not so, a factor has to be applied to increase the intake to the amount necessary to secure that the body actually absorbs 3000 i.u. daily. Absorption experiments were made on the Sheffield volunteers with a few foods, which established roughly that the amounts of carotene that had to be offered in order that $3000 \mathrm{i}$.u. should be absorbed were from carrots, boiled, sliced or made into puree 12,000 , but if the carrots were homogenized only 5500 , from cabbage or spinach 7500 , and from oil or fat 4000 . It is thus obviously highly undesirable to state the daily requirement of $\beta$-carotene as any one figure though, if it is essential to have one figure, the compromise value of 7500 , three times the vitamin A requirement, was reluctantly put forward.

The values suggested from their experiment by the Vitamin A Subcommittee do not agree too badly with the value of 5000 put forward by the National Research Council (1948) in the United States, with the note attached that the allowance is 'based on the premise that approximately two-thirds of the vitamin $\mathrm{A}$ value of the average diet in this country is contributed by carotene and that carotene has half or less than half the value of vitamin A'. If, on this basis, the mixed value of 5000 is recalculated as entirely vitamin $A$, the value obtained is 3250 or less, and if it is recalculated as all $\beta$-carotene the value is 6500 or more. These figures do not differ too excessively from the Vitamin $A$ Subcommittee's suggestions of 2500 and 7500 .

\section{REFERENCES}

Hamano, S. (1935). Sci. Pap. Inst. phys. chem. Res. Tokyo, 28, 69.

Hamano, S. (1937). Sci. Pap. Inst. phys. chem. Res. Tokyo, 32, 44.

Hume, E. M. (1937). Nature, Lond., 139, 467.

Hume, E. M. (1939). Nature, Lond., 143, 22.

Hume, E. M. (1943). Nature, Lond., 15I, 535

Hume, E. M. \& Chick, H. (1935). Spec. Rep. Ser. med. Res. Coun., Lond., no. 202.

Hume, E. M. \& Krebs, H. A. (1949). Spec. Rep. Ser. med. Res. Coun., Land., no. 264.

Mead, T. H. (1939). Biochem. F. 33, 589.

Morton, R. A. \& Stubbs, A. L. (1947). Biochem. F. 41, 525.

National Research Council: Food and Nutrition Board. (1948). Repr. nat. Res. Coun., Wash., no. 129.

Permanent Commission on Biological Standardization: League of Nations (193r). Report of the Permanent Commission on Biological Standardization. Official no. C. H. 1056 ( 1 ).

Permanent Commission on Biological Standardization: League of Nations (1934). Quart. Bull. L.o.N. Hlth Org. 3, 428.

World Health Organization: Expert Committee on Biological Standardization (1949). Report of the Subcommittee on Fat-Soluble Vitamins. WHO/BS/65 Rev. I, 